\title{
Demonstration of a relatively hepatoselective effect of covalent insulin dimers on glucose metabolism in dogs
}

\author{
F. Shojaee-Moradie ${ }^{1}$, N.C. Jackson ${ }^{1}$, M. Boroujerdi' ${ }^{1}$, D. Brandenburg ${ }^{2}$, P.H. Sönksen ${ }^{1}$, R.H. Jones ${ }^{1}$ \\ ${ }^{1}$ Department of Medicine, United Medical and Dental School, Guy's and St. Thomas's Hospitals London, UK \\ ${ }^{2}$ Deutsches Wollforschungsinstitut, Aachen, Germany
}

Summary Insulin analogues with relatively greater effect on hepatic glucose production than peripheral glucose disposal could offer a more physiological approach to the treatment of diabetes mellitus. The fact that proinsulin exhibits this property to a minor degree may suggest that analogues with increased molecular size may be less able than insulin to obtain access to peripheral receptor sites. Covalent insulin dimers have previously been shown to possess lower hypoglycaemic potencies than predicted by their in vivo receptor binding affinities. Reduced rates of diffusion to peripheral target tissues might be an explanation for the lower in vivo potency compared to insulin. To test the relative hepatic and peripheral effects of covalent insulin dimers, glucose clamp procedures with D-[3$\left.{ }^{3} \mathrm{H}\right]$ glucose tracer infusions were used in anaesthetised greyhounds to establish dose-response curves for rates of hepatic glucose production and glucose disposal with insulin, $\mathrm{N}^{\alpha \mathrm{B} 1}, \mathrm{~N}^{\alpha \mathrm{B}^{\prime} 1}$,-suberoyl-insulin dimer, and $\mathrm{N}^{\varepsilon B 29}, \mathrm{~N}^{\varepsilon B^{\prime} 29}$,-suberoyl-insulin dimer. With $\mathrm{N}^{\alpha \mathrm{B} 1}, \mathrm{~N}^{\alpha \mathrm{B}^{\prime} 1}$,-suberoyl-insulin dimer molar potencies relative to insulin were $68 \%,(34-133)$ (mean and $95 \%$ fiducial limits), for inhibition of hepatic glucose production and $14.7 \%,(10.3-20.9)$ for glucose disposal. With $\mathrm{N}^{\varepsilon \mathrm{B} 29}, \mathrm{~N}^{\varepsilon \mathrm{B}^{\prime}} 29$,-suberoyl-insulin dimer potencies were $75 \%,(31-184)$ and $2.5 \%$, (1.5-4.3), for inhibition of hepatic glucose production and for glucose disposal, respectively. The demonstration that both dimers exhibit a significantly greater effect on glucose production than on glucose disposal supports the suggestion that analogues with increased molecular size may exhibit reduced ability to gain access to peripheral target cells. [Diabetologia (1995) 38: 1007-1013]

Key words Insulin, insulin analogues, glucose metabolism, euglycaemic clamp, insulin action, hepatoselectivity, glucose production.
Insulin influences glucose metabolism in vivo by inhibiting hepatic glucose production $(\mathrm{Ra})$ and by stimulating peripheral glucose disposal ( $\mathrm{Rd}$ ) mostly in skeletal muscle [1]. There have been suggestions that

Received: 21 September 1994 and in revised form: 16 February 1995

Corresponding author: Dr. F. Shojaee-Moradie, Department of Medicine, UMDS, St. Thomas' Hospital, Lambeth Palace Road, London SE1 7EH, UK

Abbreviations:B1-B' $1 \mathrm{D}, \mathrm{N}^{\alpha \mathrm{B} 1}, \mathrm{~N}^{\alpha \mathrm{B}^{\prime} 1}$,-suberoyl-insulin dimer; $\mathrm{B} 29-\mathrm{B}^{\prime} 29 \mathrm{D}, \mathrm{N}^{\mathrm{B} 29}, \mathrm{~N}^{\varepsilon \mathrm{B}^{\prime} 29}$,-suberoyl-insulin dimer; Ra, hepatic glucose production rate; $\mathrm{Rd}$, peripheral glucose disposal rate; $\mathrm{M}_{\mathrm{r}}$, relative molecular weight; $\mathrm{MCR}$, metabolic clearance rate; ANOVA, analysis of variance. some insulin analogues differ in their potencies relative to insulin for these two separate actions on glucose metabolism [2]. The most well-established quantitative data are derived from extensive studies with human proinsulin. It has been reported that proinsulin, in comparison to insulin, is more effective in the liver than in the periphery [3-5]. The reasons for this are not yet understood.

It is now established that insulin exhibits its biological effects by binding to specific receptors located at the surface of the target cells [6]. The availability of a hormone at the receptor sites in the target tissues is one determinant of its physiological effect. Endothelial cells in peripheral tissues, although less impermeable than the blood-brain barrier, nevertheless 
limit the transfer of materials from the circulation into the tissues with the relative rate of diffusion inversely related to molecular size [7]. In contrast hepatocytes are freely in contact with all blood constituents in the hepatic sinusoids. Recently developed insulin analogues which remain monomeric $\left(M_{r} \approx 6000\right)$ at concentrations used therapeutically are absorbed substantially more quickly from subcutaneous depot injection sites than conventional preparations of soluble insulin which remain predominantly hexameric under such circumstances $[8,9]$. It is therefore clear that molecular size can influence the rate of transfer of insulin from the tissues into the blood. Conversely, the observations that proinsulin $\left(M_{r} \approx 9000\right)$ exhibits a relatively greater effect on $\mathrm{Ra}$ than RD [4], could be explained if transfer of analogues with increased molecular size out of the circulation into peripheral tissues was similarly reduced in comparison to the rate of transfer of insulin. We have compared the effects of insulin $\left(M_{r} \approx 6000\right)$ and two covalently bound insulin dimers (MW 11604) on $\mathrm{Ra}$, and $\mathrm{Rd}$ in anaesthetised greyhounds.

\section{Materials and methods}

Materials. B1-B' $1 \mathrm{D}$ and B29-B' 29D were prepared as previously described [10]. Semi-synthetic human insulin was purchased from Novo Laboratories (Novo Research Institute, Bagsvaerd, Denmark).

Experimental protocol. Euglycaemic glucose clamp procedures [11] each with two rates of infusion of either insulin or one of the two insulin dimers were performed in random order on three intact, adult, overnight fasted anaesthetised greyhounds weighing $28-36 \mathrm{~kg}$. The protocols were approved by the United Kingdom licensing authority for animal experimentation. Each complete study comprised six separate 8 -h experiments (protocols 1 and 2) with an interval of at least 4 weeks between the experiments. Anaesthesia was induced by intravenous injection of sodium pentobarbitone $(30 \mathrm{mg} / \mathrm{kg}$ body weight). The dogs were ventilated at minute volumes previously shown to maintain normal blood oxygen and carbon dioxide concentrations [12]. The body temperature was maintained at $37^{\circ} \mathrm{C}$ using a heating pad. Catheters were inserted into a cephalic vein for the infusion of D-glucose and D-[3${ }^{3} \mathrm{H}$ ]glucose, a lateral saphenous vein for infusion of insulin or dimers and an external jugular vein for blood sampling. Following an intravenous priming dose $(50 \mu \mathrm{Ci})$ of $\mathrm{d}-[3-$ ${ }^{3}$ H]glucose (Radiochemical Centre, Amersham Ltd, Chalfont, Bucks., UK) a continuous infusion of $\mathrm{D}-\left[3{ }^{3} \mathrm{H}\right]$ glucose $0.5 \mu \mathrm{Ci} /$ min was initiated. After 120 min for equilibration of glucose tracer and a 30-min period for baseline observation a primed two-step infusion of insulin or dimer was started.

Insulin or dimer for infusion was diluted into $0.9 \%(\mathrm{w} / \mathrm{v})$ sodium chloride in water containing $1 \%(\mathrm{w} / \mathrm{v})$ human serum albumin (Blood Products Laboratory, Therapeutics Division, Elstree, Herts., UK) to achieve infusion rates of 3.4 and 13.8 $\mathrm{pmol} \cdot \mathrm{kg}^{-1} \cdot \min ^{-1}$ (insulin), 5.0 and $24.8 \mathrm{pmol} \cdot \mathrm{kg}^{-1} \cdot \mathrm{min}^{-1}$ (B1-B' 1 D and B29-B' 29 D) in protocol 1 and 6.9 and 68.9 $\mathrm{pmol} \cdot \mathrm{kg}^{-1} \cdot \mathrm{min}^{-1}$ (insulin), 10.0 and $49.5 \mathrm{pmol} \cdot \mathrm{kg}^{-1} \cdot \mathrm{min}^{-1}$ (B1-B' 1 D and B29-B' 29 D) in protocol 2. Priming doses were calculated assuming an apparent distribution space of $100 \mathrm{ml} /$ $\mathrm{kg}$ [2] and previously published values for insulin and insulin dimer clearance rates in dogs [12]. After $120 \mathrm{~min}$ the infusion rate was increased following a second appropriate priming dose and continued for a further $120 \mathrm{~min}$. Four blood samples were drawn at 10-min intervals for immediate determination of basal (120-150 $\mathrm{min})$ plasma glucose concentration. After the initiation of insulin or dimer infusion $(150 \mathrm{~min})$, blood samples were drawn at 5 -min intervals to $480 \mathrm{~min}$ for serum glucose determination in order to maintain the glucose clamp. An infusion of $50 \%(\mathrm{w} / \mathrm{v}) \mathrm{D}$-glucose in water was modulated to maintain euglycaemia. Blood samples were also collected every $30 \mathrm{~min}$ and at 10-min intervals from 120-150 min (baseline determination), $240-270 \mathrm{~min}$ and $360-390 \mathrm{~min}$ for determination of immunoreactive insulin and glucose concentrations and the plasma glucose specific activity. Insulin or dimer infusion was discontinued at $390 \mathrm{~min}$. Blood sampling was continued every $5 \mathrm{~min}$ to $430 \mathrm{~min}$ and at 10 -min intervals thereafter for the measurements of plasma glucose specific activity and insulin or dimer concentration. Serum and plasma samples were stored at $-20^{\circ} \mathrm{C}$ until assayed (within 2 weeks). Insulin and dimer concentrations were determined in serum samples and in the infusion mixtures by double antibody radioimmunoassay [13]. Iodinated human insulin was used as labelled ligand in the radioimmunoassay of insulin and covalently linked insulin dimers. Both dimers and insulin showed similar cross-reactivity with the antibody selected. For estimation of dimer concentrations appropriate in vitro dilutions of each dimer were used as standards within the assay. The within-assay coefficient of variation was $6 \%$. Plasma and infused glucose concentrations were measured using a glucose oxidase technique on a model 23 AM glucose analyser (Clandon Scientific Ltd, Yellow Springs, Ohio, USA). Within-assay coefficient of variation at $5 \mathrm{mmol} / 1$ was $3.5 \%$. Glucose specific activity was determined in duplicate on deproteinized plasma and tracer infusate according to the method of Somogyi [14], lyophilised, reconstituted in distilled water then counted in Pico Fluor 15 scintillant on a liquid scintillation counter (1219 Rackbeta; LKB, Turku, Finland).

Calculations. Values for total and endogenous $\mathrm{Ra}$ at all time points were calculated by the method of Mari [15] in which the glucose concentration and specific activity data are smoothed by a modified version of the optimal segments programme [16]. This output is applied to a two compartment model of glucose distribution and metabolism. As in this experimental protocol euglycaemia was maintained constant by a variable infusion of exogenous glucose, total $\mathrm{Ra}$ has been taken to represent Rd. Values of the metabolic clearance rate (MCR) of the hormones were calculated from their concentrations during the last $30 \mathrm{~min}$ of each infusion period. No correction was made for persisting endogenous insulin secretion which in these studies was not actively suppressed.

MCR $\left(\mathrm{ml} \cdot \mathrm{kg}^{-1} \cdot \mathrm{min}^{-1}\right)=$ infusion rate $\left(\mathrm{pmol} \cdot \mathrm{kg}^{-1} \cdot \mathrm{min}^{-1}\right)$ $\div$ serum hormone concentration $(\mathrm{pmol} / \mathrm{ml})$.

MCR of glucose was calculated from the glucose concentration during the last $30 \mathrm{~min}$ of each infusion period.

MCR $\left(\mathrm{ml} \cdot \mathrm{kg}^{-1} \cdot \mathrm{min}^{-1}\right)=$ glucose $\mathrm{Rd}\left(\mu \mathrm{mol} \cdot \mathrm{kg}^{-1} \cdot \mathrm{min}^{-1}\right)$ $\div$ plasma concentration (mmol/1).

\section{Statistical analysis}

The last $30 \mathrm{~min}$ of each infusion period was considered for statistical analysis. For comparison between groups two-way analysis of variance (ANOVA) was used and the significance of differences between the means tested by Fisher's least squares 
test using Number Cruncher Statistical System software (Hintz, Kaysville, Utah, USA). The results are expressed as arithmetic mean \pm SEM and $p$-values less than 0.05 were considered statistically significant. Potency estimates for each dimer compared with insulin were obtained from the linear portion of the log-dose response curves using the parallel line bioassay technique described by Finney [17]. Results are expressed on a molar basis, i. e.: Only one of the two insulin moieties in a dimer would need to be fully active to produce a calculated potency of $100 \%$.

\section{Results}

\section{Serum insulin and dimer concentrations}

Protocol 1. Serum insulin, B1-B' 1 D and B29-B' 29 D concentrations are shown in Figure 1. Following infusion of insulin at 3.4 and $13.8 \mathrm{pmol} \cdot \mathrm{kg}^{-1} \mathrm{~min}^{-1}$, insulin concentrations were $0.21 \pm 0.02(240-270 \mathrm{~min})$ and $1.41 \pm 0.29 \mathrm{nmol} / \mathrm{l}(360-390 \mathrm{~min})$, respectively. These insulin concentrations were significantly different from basal levels $(0.07 \pm 0.01 \mathrm{nmol} / \mathrm{l}) p<0.01$. Apparent basal insulin concentrations in the studies with dimers, i.e.: assayed against dimer standards were all less than $0.06 \mathrm{nmol} / 1$. Following infusion of dimers at 5.0 and $24.8 \mathrm{pmol} \cdot \mathrm{kg}^{-1} \cdot \mathrm{min}^{-1}$, concentrations of B1-B' $1 \mathrm{D}$ were $0.60 \pm 0.58$ and $4.87 \pm 0.30$ $\mathrm{nmol} / 1$ and $\mathrm{B} 29-\mathrm{B}^{\prime} 29 \mathrm{D}$ were $1.03 \pm 0.10$ and $5.51 \pm 0.39 \mathrm{nmol} / 1$, respectively.

Protocol 2. Following infusion of insulin at 6.9 and $68.9 \mathrm{pmol} \cdot \mathrm{kg}^{-1} \cdot \mathrm{min}^{-1}$, insulin concentrations were $0.55 \pm 0.03$ and $16.22 \pm 2.7 \mathrm{nmol} / 1$. Following infusion of dimers at 10.0 and $49.5 \mathrm{pmol} \cdot \mathrm{kg}^{-1} \cdot \mathrm{min}^{-1}$, concentrations of $\mathrm{B} 1-\mathrm{B}^{\prime} 1 \mathrm{D}$ were $1.34 \pm 0.12$ and $11.01 \pm 0.86 \mathrm{nmol} / 1$ and $B 29-B^{\prime} 29 \mathrm{D}$ were $2.08 \pm 0.38$ and $11.89 \pm 1.12 \mathrm{nmol} / \mathrm{l}$, respectively.

\section{Metabolic clearance rates of insulin and dimers}

The MCR of dimers were lower than those of insulin as seen in Figure 2. Rates were $20.3 \pm 2.49$, $8.88 \pm 0.88$ and $6.66 \pm 0.70 \mathrm{ml} \cdot \mathrm{kg}^{-1} \cdot \mathrm{min}^{-1}$ for insulin, B1-B' 1 D and B29-B' 29 D, respectively, at the lowest infusion rate, falling to $6.07 \pm 0.66,5.25 \pm 0.28$ and $5.51 \pm 0.25 \mathrm{ml} \cdot \mathrm{kg}^{-1} \cdot \mathrm{min}^{-1}$ at the highest infusion rate (Fig. 2). The decrease in MCR with increasing insulin and B1-B' $1 \mathrm{D}$ concentrations was significant $(p<0.05)$.

\section{Glucose metabolism}

Euglycaemic glucose clamp. Plasma glucose concentration was $4.8 \pm 0.03 \mathrm{mmol} / \mathrm{l}$ in the basal state and was maintained between 3.8 and $5.6 \mathrm{mmol} / 1$ during the studies, i.e.: at no time point in any experiment
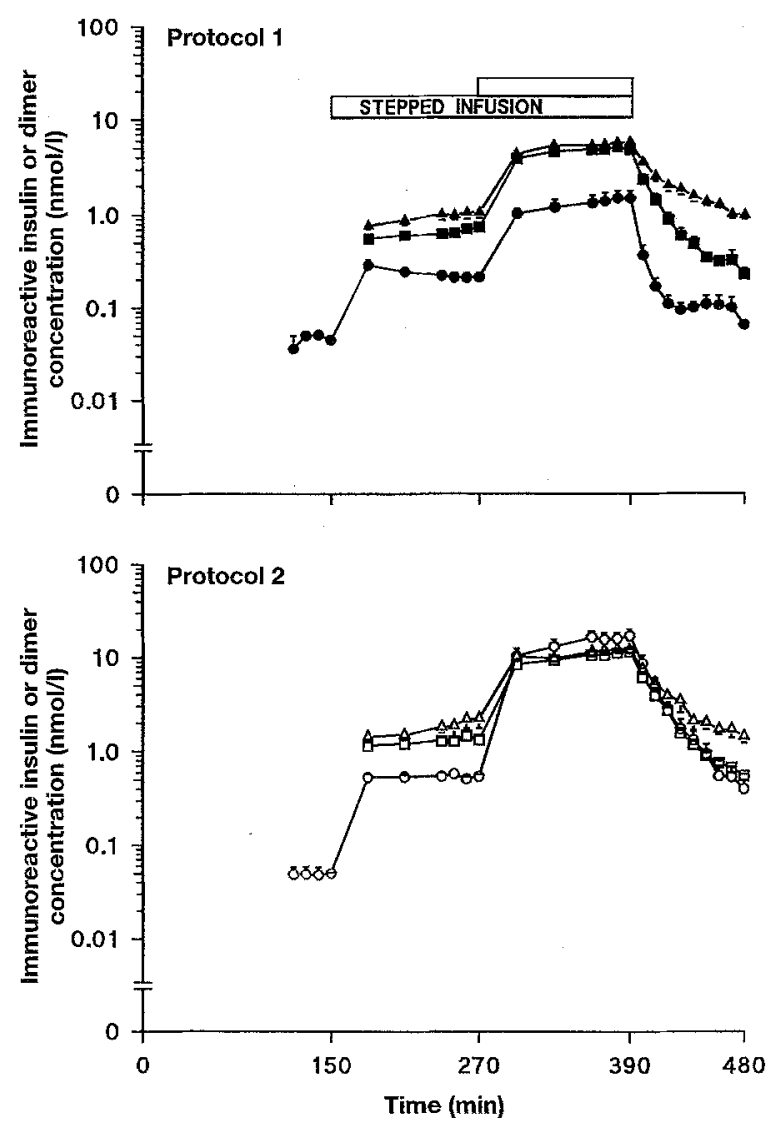

Fig. 1. Immunoreactive serum insulin $(O)(O), B 1-B^{\prime} 1 D(\square)$ $(\square)$ and B29-B' $29 \mathrm{D}(\boldsymbol{\Delta})(\triangle)$ concentrations during protocol 1 (closed symbols) and protocol 2 (open symbols) in dogs. Values are mean $\pm \operatorname{SEM}(n=3)$

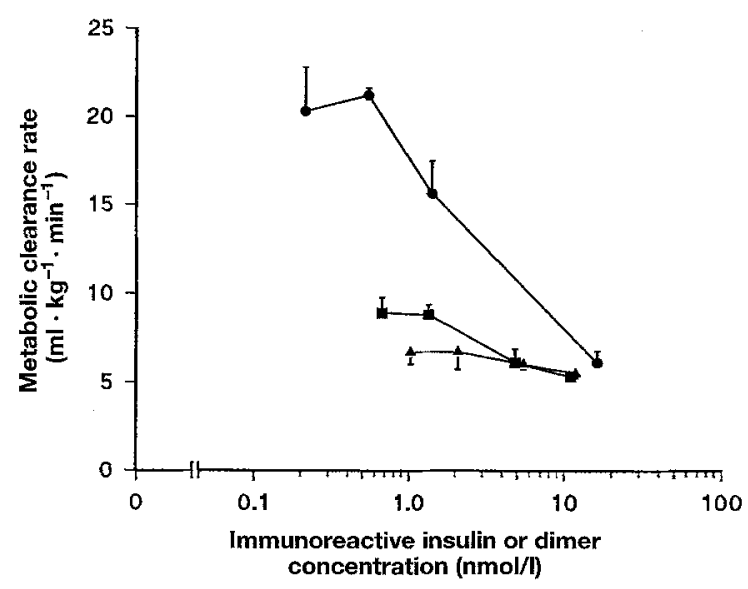

Fig. 2. Relationship between serum concentrations of insulin (O), B1-B' $1 \mathrm{D}(\mathbf{D})$ and B29-B' $29 \mathrm{D}(\mathbf{A})$ and MCR, in protocol 1 and 2 . Values are mean $\pm \operatorname{SEM}(n=3)$

was plasma glucose sufficiently raised to stimulate endogenous insulin secretion or low enough to initiate counter regulatory responses.

Hepatic glucose production rate, glucose disappearance rate and glucose metabolic clearance rate. Infu- 
sion of insulin and the dimers suppressed glucose $\mathrm{Ra}$ and increased glucose $\mathrm{Rd}, p<0.05$, (Fig. 3). Glucose $\mathrm{Ra}$ and MCR achieved with the infusion of insulin and the dimers reached an acceptable steady state in the last $30 \mathrm{~min}$ of each infusion period (240-270 min, 360-390 $\mathrm{min}$ ), Table 1. Insulin infusion at the highest rate employed $\left(68.9 \mathrm{pmol} \cdot \mathrm{kg}^{-1} \cdot \mathrm{min}^{-1}\right)$, suppressed glucose Ra significantly from a basal value of $11.9 \pm 0.9$ to $-7.7 \pm 0.9 \mu \mathrm{mol} \cdot \mathrm{kg}^{-1} \cdot \mathrm{min}^{-1}$. Glucose $\mathrm{Rd}$ increased from $11.9 \pm 0.9$ to $41.2 \pm 1.9 \mu \mathrm{mol} \cdot \mathrm{kg}^{-1}$ $\cdot \mathrm{min}^{-1},(p<0.05)$. Infusion of $49.5 \mathrm{pmol} \cdot \mathrm{kg}^{-1} \cdot \mathrm{min}^{-1}$ of B1-B' 1 D suppressed glucose $\mathrm{Ra}$ to $-7.6 \pm 1.5$ $\mu \mathrm{mol} \cdot \mathrm{kg}^{-1} \cdot \mathrm{min}^{-1}(p<0.05)$ and increased glucose $\mathrm{Rd}$ to $44.9 \pm 2.6 \mu \mathrm{mol} \cdot \mathrm{kg}^{-1} \cdot \mathrm{min}^{-1}$, whereas with B29-B' $29 \mathrm{D}$, glucose $\mathrm{Ra}$ was suppressed to $-4.4 \pm$ $1.1 \mu \mathrm{mol} \cdot \mathrm{kg}^{-1} \cdot \mathrm{min}^{-1}(p<0.05)$ and glucose $\mathrm{Rd}$ increased to $30.6 \pm 3.3 \mu \mathrm{mol} \cdot \mathrm{kg}^{-1} \cdot \mathrm{min}^{-1}$. Dose response curves were constructed for glucose $\mathrm{Ra}$ and $\mathrm{Rd}$ (Fig.3). Dose response curves were not significantly non-parallel. Molar potencies of B1-B'1 D and B29B $^{\prime} 29$ D relative to insulin are shown in Table 2.

Both dimers exhibited capacities to reduce glucose Ra which were not significantly different from that of insulin itself but displayed significantly reduced abilities to stimulate Rd.

\section{Discussion}

This study was undertaken to examine the differential effects of human insulin and two covalently linked insulin dimers B1-B' 1 D and B29-B' 29 D on the rates of glucose $\mathrm{Ra}$ and glucose $\mathrm{Rd}$ using a hyperinsulinaemic euglycaemic clamp technique. The results reported here demonstrate that the rates of glucose $\mathrm{Rd}$ following infusion of the dimers were significantly lower relative to insulin while the rates of glucose production by the liver were similar, despite the fact that higher infusion rates of the dimers were used.

These dimers also exhibited slower rates of metabolism compared to insulin, in agreement with earlier studies using lower infusion rates and during hypoglycaemia [12]. The effect of the persisting endogenous insulin secretion on these values can be considered although not accurately quantitated. Comparison of the basal concentration with those after infusion suggests that this source of error may well have affected the value for insulin MCR at the lowest rate of infusion (Figure 2). Differences between B1-B' 1 D and B29-B' 29 D are of interest.It is clear from Figure 1 that although they exibit similar steady-state levels at the end of the infusion periods the decay curves are different. The most likely explanation is that there are differences of distribution even between the two dimers. The fact that the decay curve is not linear on a semi-logarithmic plot as in Figure $1 \mathrm{im}$ plies that two or more compartments are involved.

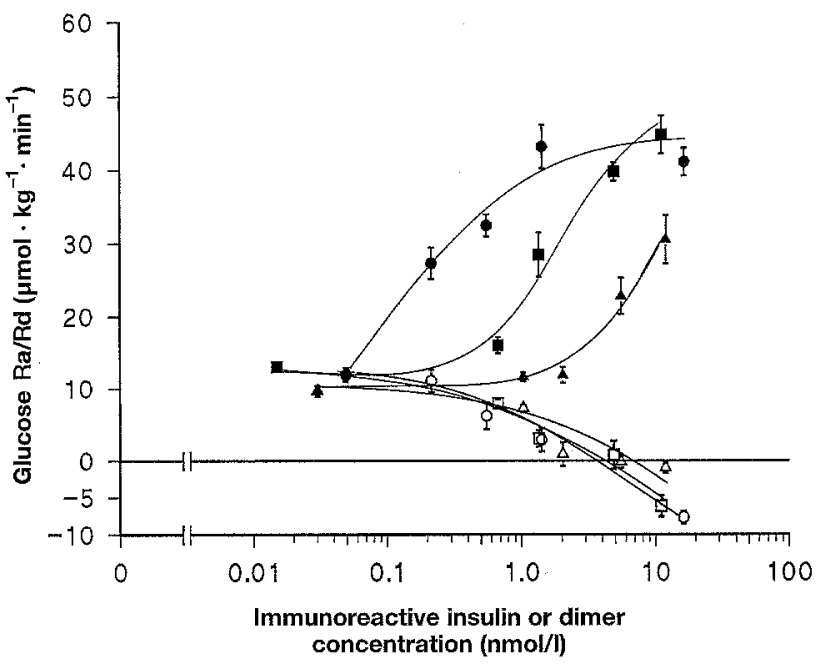

Fig. 3. Dose response relationships of glucose Rd (closed symbols) and glucose Ra (open symbols) to serum concentrations of insulin (O) (O), B1-B'1 D ( $(\square)$ and B29-B'29 D $(\Delta)(\triangle)$. Values are mean \pm SEM of the last $30 \mathrm{~min}$ of the infusions

The observations are therefore compatible with our suggestion that the dimers differ from insulin (and from each other) in their rates of diffusion across the barriers between tissue compartments.

There are considerable methodological problems associated with accurate measurement of glucose $\mathrm{Ra}$. Under non-steady-state conditions absolute values may be subject to error due to lack of adequately rapid mixing between unlabelled and labelled pools in different physiological compartments $[18,19]$. One common manifestation of these problems of equilibration is the generation of apparently negative values for glucose $\mathrm{Ra}$ at high insulin concentrations. The use as here of two compartment models has partly solved this problem but as can be seen in Figure 3 the highest concentrations of insulin and of $\mathrm{B} 1-\mathrm{B}^{\prime} 1 \mathrm{D}$ have still led to apparently negative $\mathrm{Ra}$ values. In these experiments no effort was made to maintain glucose specific activity by variable rates of glucose tracer infusion. Such measures can reduce although not abolish equilibration errors in the estimation of glucose turnover [18]. It could be argued that differences in this error could lead to an erroneous apparent hepatoselectivity. However, the magnitude of the error in estimation of $\mathrm{Ra}$ will decrease as $\mathrm{Rd}$ decreases. The greater the $\mathrm{Rd}$ value the greater will be the underestimation of Ra. With two analogues of different biopotencies but equal relative abilities to influence $\mathrm{Ra}$ and $\mathrm{Rd}$ the error under discussion could lead to the conclusion that the more effective analogue would be relatively hepatoselective. The potential problem therefore adds confidence to our finding that the less potent dimers are in fact the materials which display such an effect.

Insulin analogues with modification of the B1 position have been shown to retain their biological prop- 
Table 1. Glucose $\mathrm{Ra}\left(\mu \mathrm{mol} \cdot \mathrm{kg}^{-1} \cdot \mathrm{min}^{-1}\right)$ and glucose MCR $\left(\mathrm{ml} \cdot \mathrm{kg}^{-1} \cdot \mathrm{min}^{-1}\right)$ at $90,100,110$ and $120 \mathrm{~min}$ after initiation of each infusion rate, i. e.: $240-270 \mathrm{~min}$ and $360-390 \mathrm{~min}$

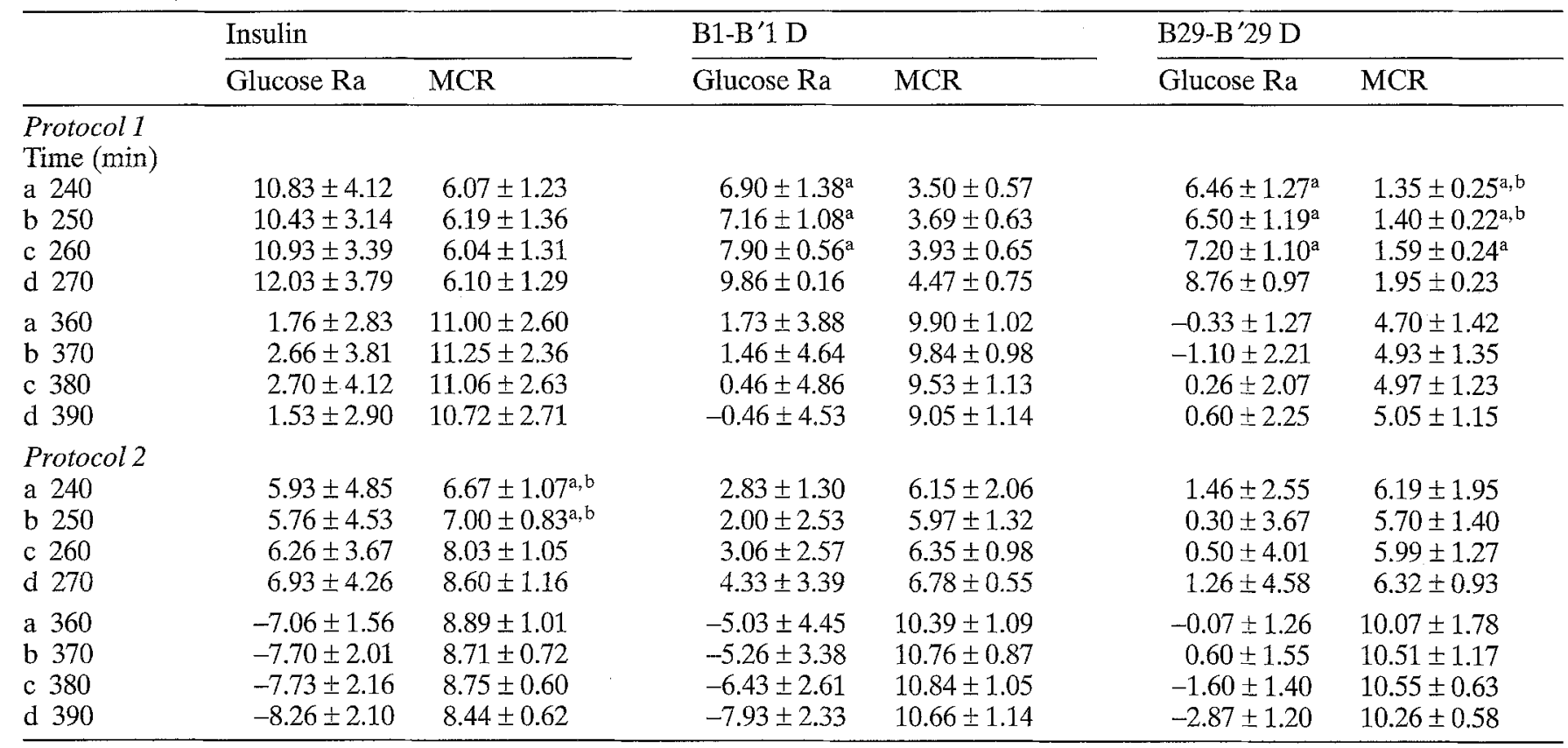

Values are mean \pm SEM. ${ }^{a}$ Significantly different from $\mathrm{d}, p<0.05$; ${ }^{\mathrm{b}}$ Significantly different from $\mathrm{c}, p<0.05$

Table 2. Molar potencies with $95 \%$ fiducial limits of B1-B'1 D and B29-B'29 D relative to insulin

\begin{tabular}{llc}
\hline & Glucose Ra & Glucose Rd \\
\hline Insulin & $100 \%$ & $100 \%$ \\
B1-B'1 D & $68 \%(34-133)$ & $14.7 \%(10.3-20.9)$ \\
B29-B'29 D & $75 \%(31-184)$ & $2.5 \%(1.5-4.3)$ \\
\hline
\end{tabular}

erties in vivo and in vitro. Insulin tracers labelled with ${ }^{125} \mathrm{I}$ or ${ }^{3} \mathrm{H}$ on $\mathrm{B} 1$ have been shown to behave like native insulin and to display similar MCR values [20, 21]. Studies with insulin analogues which differ from insulin at the B29 position in dogs have shown that these modifications have little effect on the biological activity or clearance of the hormone [2]. It seems likely, therefore, that the differential potencies reported here relate to the dimeric nature of the analogues rather than to an intrinsic effect of either a B1 or B29 modification.

One possible explanation for our findings on $\mathrm{Ra}$ (effect on the liver) and $\mathrm{Rd}$ (effects on the periphery) relates to the recent suggestion that the insulin receptor structure is to some extent tissue specific [22]. The receptor-dimer interaction may vary in different tissues, though when dimer binding affinities were compared in vitro in isolated liver plasma membranes and adipocytes, they were not different [23]. Although there is no published evidence in dogs, tissue heterogeneity in the structure of the insulin receptor has been reported in the rat [24] and human [25].

Another possible explanation for the differential effect on glucose $\mathrm{Ra}$ and $\mathrm{Rd}$ could be lower accessi- bility of the insulin dimers to the peripheral insulin receptors compared to the liver receptors. Such lower accessibility could result from a receptor-mediated transport process through vascular endothelium [26] or differences relating to molecular sieving through the capillary wall and the interstitial space $[7,27]$. In vitro studies on the kinetics of lipogenic activity of insulin in fat cells in comparison to fat pad and perfused fat pad suggested limitation of access of insulin to its receptor in perfused fat pad preparations [28]. This can be compared to our animal model where insulin or the dimers of insulin were delivered into a peripheral vein. In order to induce their biological effect in the periphery they have to traverse the endothelial barrier and interstitial fluid to reach the receptors. In the liver the microanatomy is completely different, with no barrier between the liver sinusoids and the surface of hepatocytes. Easy access of insulin and insulin analogues to the binding sites in the liver has been clearly demonstrated in rats [29].

Peripheral administration of proinsulin has been shown to exert a relatively greater effect on $\mathrm{Ra}$ than $\mathrm{Rd}[3,5]$, when compared with insulin although the differential was less than we have shown here with these insulin dimers. These observations are compatible with a mechanism dependent on molecular size as proinsulin is intermediate in molecular weight between insulin and insulin dimers.

In studies in dogs where the concentration of insulin in the lymphatic fluid was compared to plasma insulin, concentrations in lymph were lower than those in plasma and correlated better with $\mathrm{Rd}$ [30]. Recent 
data from human subjects using microdialysis has clearly established the existence of a barrier to transport of insulin from the vascular to the interstitial space [31]. We suggest that this endothelial barrier which exists in the periphery but not in the liver plays an important physiological role in determining access of peptides to receptor sites on muscle cells and other peripheral tissues.

It is of interest that analogues of insulin which remain monomeric $\left(M_{r} \approx 6000\right)$ when administered subcutaneously $[9,32]$, have been shown to appear in the plasma from the subcutaneous depots faster than conventional insulins which are largely hexameric $\left(M_{r} \approx 36000\right)$ in the formulations in which they are injected.

In infusion studies in man where the analogues were delivered at high dilution into a peripheral vein, under circumstances in which insulin itself will be largely monomeric glucose $\mathrm{Ra}$ and $\mathrm{Rd}$ responses were found to be the same for the two monomeric insulin analogues and human insulin suggesting no enhancement of access of these analogues to peripheral sites in comparison to insulin [32].

The results suggest a difference in potency of the two dimers for Rd with respect to insulin. This could reflect differences in accessibility to tissue receptors in spite of the similar molecular mass if in solution the shape adopted by the dimers differed. The possibility that these observations could derive from different capacities of the two dimers to bind with or activate insulin receptors needs to be considered [23]. Analogues with reduced receptor binding potency retain in vivo bioactivity because the increased concentration which results from the lower receptor-mediated MCR compensates for the lower affinity [33]. This effect applies equally to hepatic and peripheral activities as it is related to plasma concentration. Therefore, for a dissociation to be apparent between the hepatic and peripheral potencies a phenomenon additional to such reduced affinity should apply. We suggest that a barrier to peripheral transport provides such a mechanism and that insulin dimers are sufficiently bigger than the monomer for this effect to be apparent.

In conclusion, it appears that the molecular size of an insulin analogue may play an important role in controlling its rate of transfer through capillary endothelial barriers. Insulin-like moieties of high molecular weight, therefore, appear relatively hepatoselective when administered intravenously in vivo. Such hepatoselectivity could allow development of insulin analogues which when peripherally administered for example by subcutaneous injection would more closely reflect the natural balance of activity of native pancreatic insulin for which hepatoselectivity is conferred by virtue of its delivery directly into the portal circulation. Such an analogue could conceivably be monomeric on injection but acquire an in- creased molecular weight for example by protein binding on reaching the circulation.

Acknowledgements. This work was supported by a grant from the British Diabetic Association. We are grateful to Dr. A. Mari for the gift of modelling software.

\section{References}

1. Prager R, Wallace P, Olefsky JM (1986) In vivo kinetics of insulin action on peripheral glucose disposal and hepatic glucose output in normal and obese subjects. J Clin Invest 78: 472-481

2. Tompkins CV, Brandenburg D, Jones RH, Sönksen PH (1981) Mechanism of action of insulin and insulin analogues. Diabetologia 20: 94-101

3. Sönksen PH, Tompkins CV, Srivastava MC, Nabarro JDW (1973) A comparative study of human insulin and porcine proinsulin in man. Clin Sci Mol Med 45: 633-654

4. Lavelle-Jones M, Scott MH, Kolterman O et al. (1987) Selective suppression of hepatic glucose output by human proinsulin in the dog. Am J Physiol 252: E230-E236

5. Glauber H, Revers R, Henry R et al. (1986) In vivo deactivation of proinsulin action on glucose disposal and hepatic glucose production in normal man. Diabetes 35: 311-317

6. Gliemann J, Sonne O (1978) Binding and receptor-mediated degradation of insulin in adipocytes. J Biol Chem 253: 7857-7863

7. Rossing N, Worm AM (1981) Interstitial fluid: exchange of macromolecules between plasma and skin interstitium. Clin Physiol 1: 275-284

8. Vora JP, Owens DR, Dolben J et al. (1988) Recombinant DNA derived monomeric insulin analogues: comparison with soluble human insulin in normal subjects. BMJ 297 : 1236-1239

9. Brange J, Ribel V, Hansen JFet al. (1988) Monomeric insulins obtained by protein engineering and their medical implications. Nature 333: 670-682

10. Schüttler A, Brandenburg D (1982) Preparation and properties of covalently linked insulin dimers. Hoppe-Seyler's Z Physiol Chem 363: 317-330

11. DeFronzo RA, Tobin JD, Andres R (1972) Glucose clamp technique: a method for quantifying insulin secretion and resistance. Am J Physiol 237: E214-E223

12. Tatnell M, Jones RH, Sönksen PH (1984) Covalently linked insulin dimers. Their metabolism and biological effects in vivo as partial competitive antagonists of insulin clearance. Diabetologia 27:27-31

13. Sönksen PH (1976) Double antibody technique for simultaneous assay of insulin and growth hormone. In: Antoniades HN (eds) Hormones in human blood: detection and assay. Harvard University Press, Cambridge, Massachusetts USA, London, pp 176-199

14. Somogyi MJ (1945) Determination of blood glucose. J Biol Chem 160: 69-73

15. Mari A (1992) Estimation of the rate of appearance in the non-steady state with a two compartment model. Am J Physiol 263: E400-E415

16. Finegood DT, Thomaseth K, Pacini G, Bergman RN (1988) OPSEG: a general routine for smoothing and interpolating discrete biological data. Comput Methods Program Biomed 26: 289-300

17. Finney DJ (1964) Parallel line bioassays. Statistical methods in biological assay, 2nd edn. Griffin, London, pp 99 138 
18. Finegood DT, Bergman N, Vranic M (1987) Estimation of endogenous glucose production during hyperinsulinaemiceuglycaemic glucose clamps. Comparison of unlabelled and labelled exogenous glucose infusates. Diabetes 36 : 914-924

19. Finegood DT, Bergman N, Vranic M (1988) Modelling error and apparent isotope discrimination confound estimation of endogenous glucose production during euglycaemic glucose clamps. Diabetes 37: 1025-1034

20. Cockram CS, Jones RH, Boroujerdi MA, Sönksen PH (1984) Evidence for separate handling in vivo of different regions of the insulin molecule using A14- and B1-labelled insulin tracers. Diabetes 33: 721-727

21. Halban PA, Offord RE (1975) The preparation of semisynthetic tritiated insulin. Biochem J 151: 219-225

22. De Pirro R, Borboni P, Lauro R et al. (1985) Tissue-specific antibodies against the fibroblast insulin receptor in a patient with lupus nephritis and hypoglycaemia. Diabetes 34 : 1088-1092

23. Tatnell MA, Jones RH, Wiley KP, Schüttler A, Brandenburg D (1983) Evidence concerning the mechanism of insulin-receptor interaction and the structure of the insulin receptor from biological properties of covalently linked insulin dimers. Biochem J 216: 687-694

24. Burant CF, Treutelaar MK, Block NE, Buse MG (1986) Structural differences between liver- and muscle-derived insulin receptors in rats. J Biol Chem 261: 14361-14364

25. Sesti G, Marini MA, Montemurro A et al. (1992) Evidence that two naturally occurring human insulin receptor-subunit variants are immunologically distinct. Diabetes 41: 611
26. King GL, Johnson SM (1985) Receptor-mediated transport of insulin across endothelial cells. Science 227: 1583-1586

27. Watson PD, Bell DR, Renkin EM (1980) Early kinetics of large molecule transport between plasma and lymph in dogs. Am J Physiol 239: H525-H531

28. Chernick SS, Gardiner RJ, Scow RO (1987) Restricted passage of insulin across capillary endothelium in perfused rat adipose tissue. Am J Physiol 253: E475-E480

29. Jensen I, Kruse V, Larsen UD (1991) Scintographic studies in rats. Kinetics of insulin analogues covering wide range of receptor affinities. Diabetes 40: 628-632

30. Ader M, Poulin RA, Yang YJ, Bergman RN (1992) Doseresponse relationship between lymph insulin and glucose uptake reveals enhanced insulin sensitivity of peripheral tissues. Diabetes 41: 241-253

31. Jansson P-AE, Fowelin JP, Von Schenck HP, Smith UP, Lönnroth PN (1993) Measurement by microdialysis of the insulin concentration in subcutaneous interstitial fluid. Importance of the endothelial barrier for insulin. Diabetes 42: 1469-1473

32. Kang S, Brange J, Burch A, Voland A, Owens DR (1991) Subcutaneous insulin absorption explained by insulin's physicochemical properties. Evidence from absorption studies of soluble human insulin and insulin analogues in humans. Diabetes Care 14: 942-948

33. Jones RH, Dron DI, Ellis MJ, Sönksen PH, Brandenburg D (1976) Biological properties of chemically modified insulins. I. Biological activity of proinsulin and insulin modified at $\mathrm{A}_{1}$-glycine and $\mathrm{B}_{29}$-lysine. Diabetologia 12: 601-608 